\title{
Application of O2O Teaching Mode in the Construction of Vocational Education Resource Database in Internet Plus Era
}

\section{Xiao Yin}

Ji Lin Justice Officer Academy, Changchun 130062, Jilin, China. E-mail: seekeryin@sina.com

Project: Research project of vocational education and adult education teaching reform in Jilin Province in 2019: Research on the application of online and offline hybrid teaching and professional teaching resource database based on O2O model (Project No.: 2019zcy188).

Abstract: With the development of the times, the influence of the Internet on people has penetrated into all aspects. "Internet plus" is the product of the integration of the times and thinking, which has the characteristics of universality and integration. "Internet plus" has gradually become the main direction of Internet development. The teaching work in the era of "Internet plus" is also developing and innovating. In the "Internet plus" occupation era, O2O teaching mode combined with occupation education has become an inevitable trend in teaching. Now, in the teaching work, the teaching resource database has completed the basic construction, playing an important role in promoting the progress of vocational education in China. But in actual circumstances, there are still many problems in the application of occupation education resource database. This paper first analyzes the $\mathrm{O} 2 \mathrm{O}$ teaching mode, and then further analyzes the problems in the application of educational resource database. Finally, it makes further research and discussion on the application improvement measures.

Keywords: "Internet Plus"; O2O Teaching Mode; Vocational Education; Education Resource Database

"Internet plus" is a new form of Internet application. After the concept was put forward, it has immediately received the attention of various industries. Because the concept of "Internet plus" has not been applied before, it needs to carry out practice. How to translate the concept of "Internet plus" into reality has turned a problem that become the focus of various industries. Most vocational schools first launched the "Internet plus" combined O2O teaching mode, and explored and carried out further training of occupation and application technology, laying a good foundation for its practical application. Therefore, as early as before, the education industry began to pay attention to the construction of education resource database. Until now, the resource database has formed a basic scale, but due to the lack of time experience, the scale of resource database construction is still different from the actual situation.

\section{Overview of $\mathrm{O} 2 \mathrm{O}$ teaching mode}

$\mathrm{O} 2 \mathrm{O}$ is a business model combining Internet and offline business. The main content of $\mathrm{O} 2 \mathrm{O}$ teaching mode is to effectively use Internet resources as teaching materials. This teaching mode makes up for the defects of only offline teaching or online teaching. To a certain extent, it combines the advantages of online + offline, and pays attention to the communication and interaction between teachers and students in the teaching process. It is mainly reflected in teachers' imparting knowledge in class and students' analysis and discussion of learning problems after class. In view of the common problems in teaching and

Copyright (C) 2020 Xiao Yin

doi: 10.18686/ahe.v4i10.2933

This is an open-access article distributed under the terms of the Creative Commons Attribution Non-Commercial License (http://creativecommons. org/licenses/by-nc/4.0/), which permits unrestricted non-commercial use, distribution, and reproduction in any medium, provided the original work is properly cited. 
learning, teachers can organize students to carry out group discussion to analyze problems together and focus on explaining to students for difficult and doubtful problems ${ }^{[1]}$.

\section{Problems in the construction of vocational education resource database in the era of "Internet plus"}

\subsection{The construction of educational resource database is not in line with the reality}

In the era of "Internet plus", sharing center for learning is the location of resource database construction, but in actual construction, it has not achieved this positioning and requirements. The database is mainly built by the host colleges and other institutions, which leads to the lack of full integration of the courses in the database, and ultimately leads to the fact that the sharing center for learning cannot achieve unified ${ }^{[2]}$.

\subsection{The sharing mechanism of educational resources is not perfect}

Due to the imperfect sharing mechanism of educational resource database, the quality of resources is generally low, so students can not improve their learning level through resource learning.

\subsection{The utilization rate of educational resources is low}

According to the data of the platform on the network and the report of the resource database, it is found that the access form of the education resource database is still relatively single. The resources in each website platform or resource database are classified according to the resource type and course type, which leads to the low utilization rate of the overall resources and the access to the teaching resource database. In addition, the quantity is unable to achieve the expected goal.

\section{Application of $\mathbf{O 2 O}$ teaching mode in the construction of vocational education resource database under "Internet plus" Era}

\subsection{Providing educational resource database and cooperating mode}

In the era of "Internet plus", the mode of co operation of constructing educational resource database mainly includes the mode of personal design and publication, collaborative construction, joint operation of courses, and cooperation of resources development. It utilizes information resources technology to fully process resources, and integrates effective and complete resources in the process of $\mathrm{O} 2 \mathrm{O}$ teaching $\operatorname{mode}^{[3]}$. In the aspect of co operation of vocational education resource database, we should follow the principle of strong and strong cooperation, to select excellent vocational colleges, vocational education publishers, internet education enterprises, etc. in the process of building and sharing resources of vocational education resource database. We need to invite multiple vocational education institutions to participate in the construction process, so as to let enterprises and colleges jointly build the education resource database and realize the cooperation of the resource database in a real sense.

\subsection{Optimizing the application mode of teaching resources}

In the construction of vocational education resource database, the requirements of "teaching" and "learning" should be met, including information courses, mobile learning, teaching resource database, interactive learning, etc ${ }^{[4]}$. First of all, in the process of building information courses, we should provide students with micro courses that are more suitable for their study and employment. The courses are generally practical, which can effectively promote the application of $\mathrm{O} 2 \mathrm{O}$ teaching mode. In addition to providing professional courses for students, micro courses also need to create artistic courses, such as life courses, teacher forum, industry introduction and other courses, so as to ensure the overall development of students. Then, in order to synchronize the resources in the education resource database with the course, and effectively assist teachers to carry out $\mathrm{O} 2 \mathrm{O}$ teaching mode in the teaching process, it is necessary to encourage social enterprises and vocational colleges to jointly build courses and constantly create students' course learning resources, in order to update the teaching resource database and keep students always walking in the forefront of learning ${ }^{[5]}$. In view of the construction of vocational education resource database, in addition to focusing on the expansion of resources and existing resources, we need to pay more attention to the application function and system content of resources. To sum up, we can understand that taking education resource database as the lead, learning and inquiry platform as well as information course platform as auxiliary, in order to provide effective conditions for 
the development of $\mathrm{O} 2 \mathrm{O}$ teaching mode in vocational colleges. In the process of teaching and learning, the integration of rich resources is not only for teachers and students to provide teaching and learning convenience, but also optimizes the application mode of resources, which have been widely used.

\subsection{Creating access form of educational resource database}

In the teaching process of vocational colleges, the application of teaching resource database must be indispensable. The way of obtaining resources also affects the use of resource library to a great extent. In the era of "Internet plus", in order to better promote the application of $\mathrm{O} 2 \mathrm{O}$ teaching mode and improve the efficiency of resource application, we need to fundamentally improve the access frequency of educational resource database. Therefore, it is necessary to create a more convenient and fast access form for users who use the database and make their visits more efficient, so as to improve the efficiency of their work and learning ${ }^{[6]}$.

How to create the access form of resource database can be implemented from the following aspects, such as developing software that can access the database at any time. Users can download and access the APP directly on the mobile phone, so that the user's access is not limited by time and place. In the software, various resources can also be connected, and relevant knowledge can be accessed around a keyword for integration. From the current access form of education resource database, some large-scale databases already have data interface and data website, and also provide access convenience for the majority of users. With the continuous construction and improvement of education resource database, the access speed and storage speed of data should be fully expanded in the future, so as to meet the development of $\mathrm{O} 2 \mathrm{O}$ teaching mode in teaching work and the resource demand of database in the future.

\section{Conclusion}

In general, under the background of Internet development, both the national economy and political culture are closely related to the construction of the resource database. "Internet plus", as a new concept put forward in the Internet era, is still in its initial stage, and it lacks practical exploration. China has gradually begun to attach importance to education. In order to promote the development of vocational colleges, the construction and improvement of vocational education resource database is imperative. In the current society, the demand for vocational education resource library is large. Only by fundamentally ensuring the practicability, quality and integrity of resources in the resource database can we ensure that the vocational education resource database will play a significant role in $\mathrm{O} 2 \mathrm{O}$ vocational teaching.

\section{References}

1. Cheng HL, Dang XX. Construction of shared educational resources database in the era of "internet plus". Software Engineering and Application 2020; 9(03): 244-250.

2. Liu XH. The application of the $\mathrm{O} 2 \mathrm{O}$ teaching mode in the "internet plus" era in occupation education. Educational Observation(second half of the month) 2018; 7(9): 130-131, 136.

3. Tian YJ, Sun S. "O2O + school enterprise cooperation" innovation mechanism mixed mode teaching reform from the perspective of new Engineering. Vocational Education Communication 2019; (8): 47-52.

4. Wen R, Zhao AC. Analysis of the combination of $\mathrm{O} 2 \mathrm{O}$ mode and modern vocational education in Internet plus Era. Asia Pacific Education 2016; (4): 148.

5. Liu SH, Wang CB, Ding XY. Brief discussion on the ways of realizing internet plus occupation education. Commercial Economy 2015; (11): 72-73.

6. Liu YC. Countermeasures for the renewal and quality assurance of teaching resources in vocational education under the learning environment. Education and Teaching Forum 2020; (26): 349-350. 